\title{
ANÁLISE DOS DADOS SOBRE RESÍDUOS SÓLIDOS NAS BASES DA PNSB E DO SNIS
}

\author{
Patricia Lopes Freire Pupin ${ }^{1}$ \\ Lívia Martinez Brumatti ${ }^{2}$ \\ Ana Claudia Giannini Borges ${ }^{3}$
}

\begin{abstract}
RESUMO
Esta pesquisa visa comparar os dados, sobre resíduos sólidos, obtidos em duas bases de informação vinculadas ao Governo Federal, a Pesquisa Nacional de Saneamento Básico - PNSB (2008) e o Sistema Nacional de Informações sobre o Saneamento - SNIS (2008 e 2013). Essas bases são utilizadas pelo Governo para a edificação de Políticas Públicas, porém possuem periodicidade de aplicação e metodologia diferentes. Para a comparação, foram utilizadas duas variáveis: "Coleta domiciliar de lixo" e "Coleta seletiva". Foi possível identificar que as informações coincidem apenas em 280 municípios para a primeira variável e em 138 para a segunda. A incoerência das informações, na maioria dos casos, indica a ineficiência das bases de dados como fontes de informação da realidade, o que pode resultar em prejuízos aos interesses e direitos da sociedade, visto o atraso e a morosidade na atuação do Poder Público. Assim, evidencia-se a preocupação quanto à continuidade das coletas, regulares ou seletivas, as quais são essenciais na determinação de boas condições de saneamento básico. Diante dessas condições, considera-se essencial a padronização e efetivação das fontes de informações, para a conquista de melhorias.
\end{abstract}

PALAVRAS-CHAVE: Resíduos Sólidos. PNSB. SNIS.

\section{ANAL YSIS OF THE DATA ON SOLID WASTE IN THE BASIS OF PNSB AND SNIS}

\begin{abstract}
This research aims to compare the data, on solid waste, obtained in two bases of information linked to the Federal Government, the National Research of Basic Sanitation - NRBS (2008) and the National System of Sanitation Information - NSSI (2008 and 2013). These bases are used by the Government for the construction of public policies, but they have different application frequency and methodology. For comparison, two variables were used: "Household waste collection" and "selective collection". It was possible to identify that the information match only in 280 municipalities for the first variable and 138 for the second. The inconsistency of the information, in most cases, indicates the inefficiency of
\end{abstract}

\footnotetext{
${ }^{1}$ Graduada em Administração (FCETM-MG) e membro do "Projeto Suporte: apoio a organizações do terceiro setor e grupos da sociedade civil em seus processos de gestão", cadastrado na Pró-Reitoria de Extensão da UNESP. E-mail: patricialopesfreire@hotmail.com.

${ }^{2}$ Graduada em Administração (FCAV/UNESP) e mestranda em Geografia (IGCE/UNESP). E-mail: livia.brumatti@hotmail.com.

${ }^{3}$ Professora da UNESP; Coordenadora do "Projeto Suporte: apoio a organizações do terceiro setor e grupos da sociedade civil em seus processos de gestão" - UNESP. Orientadora da pesquisa deste artigo. E-mail: agiannini@fcav.unesp.br.
} 


\section{Revista Nacional de}

Gerenciamento de Cidades

databases as sources of information of reality, which can result in damage to the interests and rights of the society, given the delay and the slowness in the performance of the Government. Thus, it evidences the concern about the continuity of regular or selective collections which are essential in determining good sanitation conditions. Given these conditions, it is considered essential the standardization and the effectiveness of information sources, for achieving improvements.

KEYWORDS: Solid Waste. PNSB. SNIS.

\section{ANÁLISIS DE LOS DATOS EN LA BASE DE RESIDUOS SÓLIDOS PNSB Y SNIS}

\section{RESUMEN}

Esta investigación tiene como objetivo comparar los datos de los residuos sólidos, obtenidos en dos bases de información vinculados al Gobierno Federal, la Encuesta Nacional de Saneamiento Básico ENSB (2008) y el Sistema de Información Nacional de Saneamiento - SINS (2008 y 2013). Estas bases son utilizadas por el Gobierno para la construcción de políticas públicas, pero ambas tienen diferencias en la frecuencia de aplicación y la metodología. Para la comparación, se utilizaron dos variables: "la recogida de residuos de los hogares" y "recogida selectiva". Fue posible identificar que la información coincide sólo en 280 municipios para la primera variable y 138 para la segunda. La inconsistencia de la información, en la mayoría de los casos, indica la ineficacia de las bases de datos como fuentes de información de la realidad, lo que puede resultar en daño a los intereses y derechos de la sociedad, dado el retraso y lentitud en la labor del Gobierno. Así, se destaca la preocupación por la continuidad de las recogidas, regulares o selectivos, que son esenciales en la determinación de las buenas condiciones de saneamiento. Dadas estas condiciones, se considera esencial la estandarización y la eficacia de las fuentes de información, para lograr mejoras.

PALABRAS CLAVE: Residuos Sólidos. PNSB. SNIS.

\section{INTRODUÇÃO}

O crescente descarte de resíduos sólidos (RS) nos municípios, estimulado pelo aumento do consumo, tem gerado impactos negativos ao meio ambiente e à sociedade. Essa situação tem despertado a atenção e o interesse dos Poderes Públicos quanto à destinação final dos mesmos (ALMEIDA et al., 2013), assim como da sociedade em geral.

No entanto, foi apenas a partir da primeira década do século XXI que o Estado Brasileiro passou a instituir leis, decretos e outros, com o objetivo de regulamentar e orientar "as questões referentes à gestão e ao gerenciamento adequado dos resíduos sólidos." (SÃO PAULO, 2010).

O tema começou a ser discutido desde o início da década de 1990, com o Projeto de Lei no 203 de 1991, porém, somente após vinte anos de tramitação no Congresso Nacional, este projeto é transformado na Lei Ordinária $\mathrm{n} . \stackrel{0}{12.305}$ de 
Revista Nacional de

Gerenciamento de Cidades

2010 (BRASIL, 2010), conhecida como Política Nacional de Resíduos Sólidos (PNRS). Outro importante marco legal e regulatório sobre a questão dos RS foi a instituição da Lei n.․ 11.445 de 2007, nomeada Lei de Saneamento Básico (BRASIL, 2007).

Tanto a PNRS quanto a Lei de Saneamento Básico são instrumentos regulatórios do Governo Federal para orientar o gerenciamento do manejo de RS. Em seus textos, evidencia-se, entre outros, a necessidade de esclarecimento do tema de RS no Brasil, através de propostas de formação de bancos de dados e informes, com vistas à execução dos parâmetros propostos para o gerenciamento, além de divulgar as potencialidades e carências regionais.

Para tal, ambas as Leis estabelecem que sejam elaborados e implementados: Plano Nacional; Planos Estaduais; e Municipais, de forma individualizada ou consorciada com outros entes Federativos. Assim, evidencia-se a necessidade de estudos para a confecção dos Planos e da publicização destes (BRASIL, 2007, 2010).

Nesse sentido, o Governo conta, antes mesmo dessas regulamentações, com algumas bases de dados que servem para informar a situação brasileira sobre o manejo de RS, o que pode contribuir para a formulação de Políticas Públicas (IBGE, 2010; MCIDADES, 2010). Dentre essas bases ${ }^{4}$, destacam-se: a Pesquisa Nacional de Saneamento Básico (PNSB) que é realizada pelo Instituto Brasileiro de Geografia e Estatística (IBGE) $)^{5}$; e o Sistema Nacional de Informações sobre o Saneamento (SNIS) que é autodeclaratório e de responsabilidade do Ministério das Cidades (MCidades).

\footnotetext{
${ }^{4}$ De acordo com o SINIR (2015), existem vários órgãos governamentais de pesquisa sobre o tema, tais como: SINIMA (Sistema Nacional de Informação sobre o Meio Ambiente), Educares (Estratégia Nacional de Educação Ambiental e Comunicação Social para a Gestão de Resíduos Sólidos), PNLA (Portal Nacional do Licenciamento Ambiental), PNIA (Portal Nacional de Indicadores Ambientais), SNIS (Sistema Nacional de Informações sobre Saneamento), IBGE (Instituto Brasileiro de Geografia e Estatística), IPEA (Instituto de Pesquisa Econômica Aplicada), porém os mais abrangentes e importantes são as duas destacadas nesta pesquisa (SNIS e PNSB).

${ }_{5}$ O IBGE é uma entidade vinculada ao Ministério do Planejamento, Orçamento e Gestão (IBGE, 2010). Portanto a PNSB está diretamente vinculada a este Ministério.
} 
A PNSB tem a primeira pesquisa disponibilizada em 1977 e, em 1989, faz-se uma reformulação metodológica. Após, têm-se mais duas ocorrências, a de 2000 e de 2008 (IBGE, 2010). A PNSB é elaborada e realizada pelo IBGE ${ }^{6}$, o qual define e aplica os questionários, além de realizar a publicidade dos dados, através de indicadores e informes, organizados com vistas à análise pública. A publicação da PNSB ocorre dois anos após a pesquisa, sendo a última divulgada em 2010 (IBGE, 2010).

A base de dados do SNIS é resultado de uma pesquisa autodeclaratória feita junto aos municípios. Esta é realizada anualmente, sendo importante separá-la por dois períodos: de 2002 a 2008, quando alguns municípios eram convidados, por amostragem (em faixas populacionais), a responderem o questionário; e de 2009 até o momento, onde todos os municípios do país são convidados a responderem o Diagnóstico, ainda que de forma autodeclaratória. A partir de então, a não participação incorre na penalidade de não recebimento de recursos da União para a área de Saneamento Básico (MCIDADES, 2015; PUPIN; BORGES, 2015). A publicação do Diagnóstico ocorre após dois anos da coleta de dados, sendo a última publicação, em 2015, sobre os dados obtidos em 2013.

Assim, é importante destacar que a problemática que envolve os RS urbanos pode ser de difícil solução, principalmente, quando o Poder Público não tem a sua disposição informações pertinentes e corretas a respeito da realidade (PUPIN; BORGES, 2015), visto que o Governo admite fazer uso dessas bases (PNSB e SNIS) para o gerenciamento de RS e a edificação de Políticas Públicas (IBGE, 2010; MCIDADES, 2010, 2015). Dessa forma, é relevante realizar uma comparação entre ambas, para identificar se existe convergência ou divergência nos dados divulgados pelas mesmas, visto que apresentam metodologia, temporalidade e regularidade distintas.

Com isso, a presente pesquisa objetiva realizar uma análise comparativa dos dados sobre o manejo de resíduos sólidos, especificamente quanto à coleta

\footnotetext{
${ }^{6}$ A coleta desenvolvida, em 2008, pelo IBGE transcorreu por cerca 6 meses (IBGE, 2010).
} 


\section{Revista Nacional de}

Gerenciamento de Cidades

domiciliar de lixo e coleta seletiva, nas bases da PNSB/IBGE e do SNIS/Ministério das Cidades, de modo a identificar se há convergência ou divergência entre as informações disponibilizadas aos usuários.

\section{2. Métodos de Análise}

Para a comparação dos dados foram utilizadas, apenas, duas variáveis similares: Coleta domiciliar e Coleta seletiva. É importante destacar que há uma falta de padronização ${ }^{7}$ das variáveis, o que impediu a comparação entre outras.

Para a identificação das duas variáveis na base da PNSB, selecionou-se a categoria "Número de municípios com manejo de resíduos sólidos, por natureza dos serviços" (coleta domiciliar e seletiva), a qual, ao ser filtrada por município, apresenta o número: "1" quando possuem a atividade; e "0" quando não os possuem.

$\mathrm{Na}$ base do SNIS, a primeira variável foi identificada através das informações sobre "Quantidades de resíduos sólidos domiciliares e públicos totais coletados", em tonelada. A ausência de um campo abordando a simples existência da atividade sugeriu a busca da informação através da quantidade coletada, pois uma vez que se tem o valor, tem a atividade. Assim, o critério de análise da existência ou não de coleta domiciliar nas duas bases de dados se deu da seguinte forma:

Quadro 1: Critério de identificação da existência das atividades.
\begin{tabular}{|c|c|}
\hline Preenchimento do Campo & Atividade \\
\hline $\mathrm{Q} \geq 1$ & Existente \\
\hline $\mathrm{Q}=0$ & Inexistente \\
\hline Vazio & Não informada \\
\hline
\end{tabular}

Fonte: Elaborado pelas autoras.

\footnotetext{
7 A padronização é importante aos objetivos do Governo Federal, pois o mesmo visa uma interoperabilidade dos dados, ou seja, uma padronização única (SINIR, 2015). A finalidade é "estabelecer uma coordenação integrada, criando condições para que as regras de obrigatoriedade no fornecimento dos dados se estendam" a todos os órgãos do Governo (MCidades, 2010, p. 6). Há ainda uma questão metodológica desde a constituição das bases espaciais do SNIS, para que as mesmas fossem compatíveis com o próprio IBGE (PUPIN; BORGES, 2015, p. 5).
} 
A variável coleta seletiva foi facilmente identificada no SNIS para os períodos analisados, pois há nesta um campo específico de questionamento dessa variável, no qual os respondentes devem declarar "sim" ou "não" para a existência da atividade. No entanto, como forma de padronização, as respostas "sim" e "não" foram substituídas por "1" e "0" respectivamente, segundo os critérios do Quadro 1.

Para a análise, foram utilizados: na base da PNSB, apenas os dados de 2008, já que este é o último disponibilizado pela mesma até a realização desta pesquisa; na base do SNIS, os dados dos anos de 2008 e de 2013, pois há a mudança metodológica. Além disto, buscou-se contemplar o mesmo ano da base da PNSB e outro com dados mais recentes e que atendesse a nova metodologia.

Deve-se mencionar que para o ano de 2008, a PNSB se pauta em 5.564 municípios existentes. No entanto, seis novos municípios ${ }^{8}$ foram formalizados até 2013, totalizando 5.570 .

É importante destacar que, até o ano de 2008, a metodologia do SNIS não convidava todos os municípios brasileiros. Assim, para este ano foram convidados 527 municípios convidados, dos quais apenas 372 responderam a plataforma (MCIDADES, 2010). Já em 2013, todos os municípios do País são convidados a participar, dos quais 3.572 municípios apresentaram informações (MCIDADES, 2015).

Diante dessas ponderações, fez-se, primeiramente, uma apresentação das informações das bases por estado e por região. Em seguida, as comparações dos dados entre as bases são apresentadas em duas partes (Coleta domiciliar e seletiva) e realizadas a partir de três condições: 1) mesmo ano (2008) para as duas bases; 2) dados da PNSB de 2008 com o SNIS de 2013; e, 3) dados da mesma base (SNIS) para os anos de 2008 e 2013. As possíveis divergências ou

\footnotetext{
${ }^{8}$ Os seis novos municípios são: Paraíso das Águas - MS, Mojuí dos Campos - PA, Nazária - PI, Pinto Bandeira - RS, Balneário Rincão - SC e Pescaria Brava - SC. Cada um apresentou um histórico de emancipação política distinto, no entanto todos subsistiam como distritos de outros municípios, sendo seus dados históricos relacionados, em 2008, respectivamente, a: Costa Rica MS; Santarém - PA; Teresina - PI; Bento Gonçalves - RS; Içara - SC e; Laguna - SC (IBGE Cidades, 2015).
} 


\section{Revista Nacional de}

Gerenciamento de Cidades

União, não há uma aderência de $100 \%$ dos municípios, principalmente, por não existir uma cobrança efetiva de resposta por parte do Governo. Dessa forma, apenas $64 \%$ dos municípios brasileiros responderam ao SNIS em 2013. Deve-se ressaltar, entretanto, que, houve expressivo aumento de participantes de 2008 para 2013 (860\%), embora 1.998 municípios não tenham respondido ao questionário do SNIS em 2013. Isto pode dificultar (ou atrasar) a atuação política governamental, dado essa diferença declaratória, numa comparação com os municípios que responderam à PNSB 2008.

Ainda sobre a Tabela 1, pode-se perceber que no ano de 2008, as UFs com maior quantidade de municípios convidados, representativamente, para o SNIS, foram RJ $(28 \%)$, AC (23\%) e RR (20\%). No entanto, dos municípios convidados, as UFs que tiveram maior representatividade de resposta a SNIS foram: SP $(90 \%)$, RN (88\%), RS (88\%), PR (87\%), MG (83\%) e SC (82\%). Ressalva-se, ainda, que em todas essas UFs destacadas, os seus municípios respondentes não chegam a constituir nem $10 \%$ do total dos respectivos estados. Em 2013, período em que todos os municípios do país são convidados a participar do SNIS, as UFs com maior representatividade de municípios respondentes foram: SP (83\%), RS $(80 \%)$, PR (79\%), SC (77\%) e MS (72\%).

Ao agregar os dados em macrorregiões, observa-se ainda, para a base do SNIS 2008, que os municípios convidados apresentaram, basicamente, a mesma representatividade com relação aos municípios totais por macrorregião, variando entre 8 a $11 \%$. Fator esse que representa coerência da equipe técnica que elaborou as chamadas. Sendo que, desses municípios convidados, as regiões Sul e Sudeste apresentaram a maior quantidade de municípios informantes da base neste ano, $86 \%$ e $81 \%$, respectivamente (TABELA 2). 

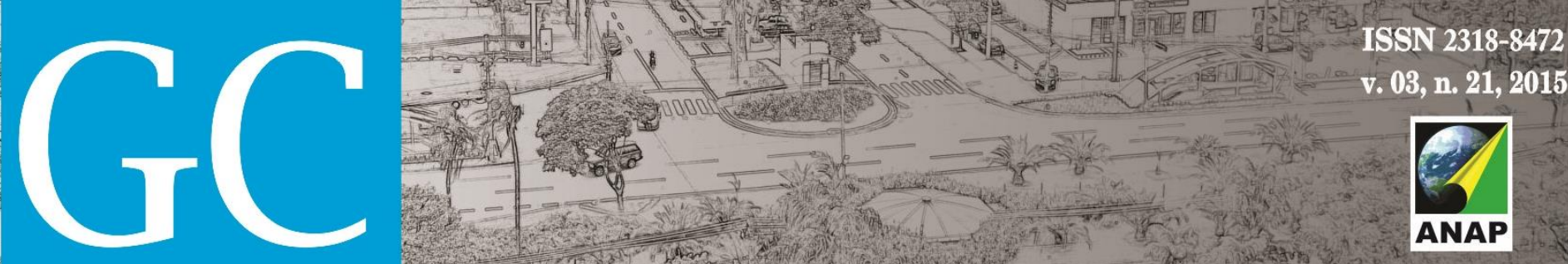

Revista Nacional de

Gerenciamento de Cidades

Tabela 2: Quantidade de municípios, respondentes às bases de dados, por macrorregião.

\begin{tabular}{|c|c|c|c|c|c|c|c|c|c|}
\hline Região & $\begin{array}{c}\text { Quantidade } \\
\text { Municípios } \\
2008\end{array}$ & $\begin{array}{l}\text { PNSB } \\
2008\end{array}$ & $\begin{array}{c}\text { Municípios } \\
\text { participantes } \\
\text { do PNSB (\%) } \\
2008\end{array}$ & $\begin{array}{l}\text { SNIS } 2008 \\
\text { convidados }\end{array}$ & $\begin{array}{l}\text { SNIS } 2008 \\
\text { respondentes }\end{array}$ & $\begin{array}{c}\text { Municípios } \\
\text { participantes } \\
\text { do SNIS (\%) } \\
2008\end{array}$ & $\begin{array}{c}\text { Quantidade } \\
\text { Municípios } \\
2013\end{array}$ & $\begin{array}{c}\text { SNIS } 2013 \\
\text { convidados } \\
\text { que } \\
\text { responderam }\end{array}$ & $\begin{array}{c}\text { Municípios } \\
\text { participantes } \\
\text { do SNIS (\%) } \\
2013\end{array}$ \\
\hline Norte & 449 & 449 & 100 & 51 & 29 & 6,46 & 450 & 242 & 53,78 \\
\hline Nordeste & 1793 & 1793 & 100 & 174 & 95 & 5,30 & 1794 & 862 & 48,05 \\
\hline Centro-Oeste & 466 & 466 & 100 & 40 & 31 & 6,65 & 467 & 280 & 59,96 \\
\hline Sudeste & 1668 & 1668 & 100 & 170 & 138 & 8,27 & 1668 & 1248 & 74,82 \\
\hline Sul & 1188 & 1188 & 100 & 92 & 79 & 6,65 & 1191 & 940 & 78,93 \\
\hline Total & 5564 & 5564 & 100 & 527 & 372 & 6,69 & 5570 & 3572 & 64,13 \\
\hline
\end{tabular}

Fonte: Elaborada pelas autoras a partir de IBGE (2010) e MCidades (2010, 2015).

Deve-se mencionar ainda que, em 2013, a situação se mantém, isto é, as regiões Sul e Sudeste têm a maior quantidade de municípios respondentes, porém a representatividade destas $(79 \%$ e $75 \%$ respectivamente) e de todas as macrorregiões do país, diminuem nesse período.

\subsection{Coleta domiciliar regular de lixo}

Quando se observa mais atentamente a PNSB 2008, é possível verificar que dos 5.564 municípios brasileiros, 22 não apresentaram a coleta domiciliar regular de lixo (TABELA 3).

Tabela 3: Relação dos municípios sem coleta domiciliar regular de lixo.

\begin{tabular}{|c|c|c|c|c|c|}
\hline Região & UF & Município & Região & UF & Município \\
\hline Norte & AM & São Paulo de Olivença & \multirow{3}{*}{ Nordeste } & \multirow{2}{*}{ PE } & \multirow{2}{*}{$\begin{array}{l}\text { Ilha de Itamaracá } \\
\text { Itacuruba }\end{array}$} \\
\hline \multirow{7}{*}{ Nordeste } & \multirow{6}{*}{ MA } & Apicum-Açu & & & \\
\hline & & $\begin{array}{l}\text { Bacurituba } \\
\text { Brejo }\end{array}$ & & $\mathrm{PI}$ & $\begin{array}{l}\text { Lagoa de São Francisco } \\
\text { São João da Varjota }\end{array}$ \\
\hline & & $\begin{array}{l}\text { Brejo de Areia } \\
\text { Buriti }\end{array}$ & \multirow{3}{*}{ Sudeste } & MG & $\begin{array}{l}\text { Ibiraci } \\
\text { Tapira }\end{array}$ \\
\hline & & \multirow{3}{*}{$\begin{array}{l}\text { Luís Domingues } \\
\text { Presidente Sarney } \\
\text { São Benedito do Rio Preto } \\
\text { Serrano do Maranhão }\end{array}$} & & RJ & Cardoso Moreira \\
\hline & & & & SP & $\begin{array}{l}\text { Jaboticabal } \\
\text { Pitangueiras }\end{array}$ \\
\hline & & & \multirow{2}{*}{ Sul } & \multirow{2}{*}{$\mathrm{RS}$} & Arroio do Padre \\
\hline & SE & Umbaúba & & & Muitos Capões \\
\hline
\end{tabular}

Fonte: Elaborado pelas autoras a partir de IBGE (2010).

Leite (2009, p. 65) destaca que "a coleta de lixo urbano domiciliar é a principal fonte primária de captação de bens descartados em comunidades" e que a 


\section{Revista Nacional de}

Gerenciamento de Cidades

inexistência dessa atividade pode ser um dos motivos da identificação de resíduos sólidos em córregos, rios e terrenos urbanos. Neste sentido, tem-se que o estado de Maranhão, em 2008, é o que estava mais predisposto ao cenário mencionado, embora a existência da atividade não seja garantidora de boas condições de saneamento.

Além disso, deve-se ressaltar que, do total de municípios no país, 5.542 municípios apresentam coleta domiciliar regular de lixo. Quanto a este aspecto, observa-se, ainda, na Tabela 3, que nenhum dos municípios de 18 UFs apresenta a falta dessa atividade, como nos municípios da região Centro-Oeste (incluindo o Distrito Federal).

Ao realizar a comparação desses 5.542 municípios que apresentam a coleta para a PNSB 2008, com os 372 municípios participantes da base do SNIS 2008, tem-se que 334 afirmaram a existência da coleta regular de resíduos sólidos urbanos e esta informação coincidiu com as obtidas na base da PNSB, Tabela 4.

\begin{tabular}{|c|c|c|c|}
\hline & PNSB 2008 & SNIS 2008 & SNIS 2013 \\
\hline Existente & 5.542 & 334 & 3.572 \\
\hline Inexistente & 22 & 1 & \\
\hline Não Informado & - & 37 & 1.998 \\
\hline Total Convidado & & 527 & 5.570 \\
\hline Total Participante & 5.564 & 372 & 3.572 \\
\hline
\end{tabular}

O município de Sumaré - SP foi o único que declarou (no SNIS) não existir a atividade de coleta em 2008, apesar de a mesma ser identificada na PNSB, o que representa uma divergência entre as bases, ou entre a metodologia de coleta de informações das mesmas. Para os demais municípios participantes (37) da base do SNIS, em 2008, o campo não foi preenchido de maneira afirmativa ou negativa, porém esses mesmos municípios apresentam coleta regular, na PNSB.

A pouca quantidade de participantes do SNIS 2008, bem como a existência de divergências em alguns dados quando comparados aos que igualmente responderam à PNSB 2008, pode gerar atraso na formulação de políticas públicas 


\section{Revista Nacional de}

Gerenciamento de Cidades

adequadas, uma vez que, se o gestor público utilizar os dados do SNIS apenas, sem conflitar os informes da PNSB, pode ter em mãos informações díspares para o mesmo período.

Ao relacionar a base de dados da PNSB 2008 com o SNIS 2013, percebe-se que dos 22 municípios, que haviam declarado não apresentarem a atividade na PNSB 2008, 12 afirmam sua existência no SNIS 2013, o que passa a coincidir com os dados da PNSB. No entanto, duas ressalvas devem ser feitas: há uma diferença de cinco anos entre os dados; e, não foi identificado, nesta pesquisa, o ano em que o município passa a declarar a existência da atividade. Em todo caso, mesmo que os 12 municípios tivessem declarado a existência da atividade, em 2009, haveria uma diferença de um ano entre as informações, e isso pode gerar morosidade na atuação do Poder Público.

Há que se mencionar, também, que dos seis municípios que passaram a existir depois de 2008, apenas os municípios de Paraíso das Águas (MS) e Balneário Rincão (SC) declararam informações ao SNIS, apresentando a coleta domiciliar regular de lixo, o que coincide com as informações dos municípios, dos quais eram distritos anteriormente.

Ao serem comparados os dados dos diagnósticos do SNIS 2008 e 2013, observa-se que dos 334 municípios, que responderam afirmativamente no primeiro, 54 não informaram qualquer dado no ano de 2013. O município de Sumaré - SP que havia respondido negativamente, em 2008, e 27 outros municípios que não haviam respondido os dados, afirmam a existência da atividade em 2013. Tem-se, portanto, que 82 municípios, dos 372 respondentes de 2008, apresentaram informações distintas entre 2008 e 2013, para a mesma base.

Além disso, dos 5.198 municípios que não participaram do Diagnóstico no ano de 2008, 3.264 aderiram à base de dados no ano de 2013. No entanto, dos 1.998 que não responderam ao SNIS 2013, 64 haviam respondido em 2008, mesmo que tivesse não informado o campo analisado, caso de 10 municípios. Esses dados confirmam a dificuldade em se trabalhar com dados autodeclaratórios, quando não 


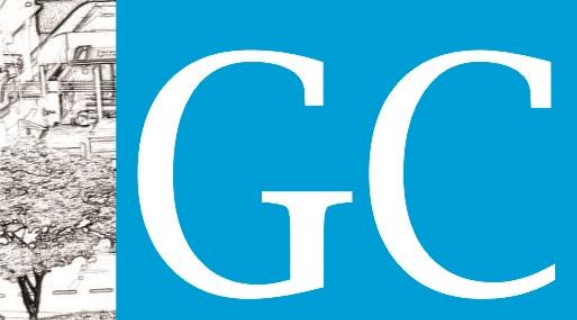

\section{Revista Nacional de}

Gerenciamento de Cidades

há um compromisso do Poder Público (declarante) na divulgação de informações, para a sua devida publicização. Ademais, apenas 280 municípios tiveram suas informações declaradas e compatíveis nos dois períodos analisados e nas duas bases (Gráfico 1).

\section{Gráfico 1: Quantidade e representatividade dos municípios com informações coincidentes nas} duas bases, por Unidade Federativa.

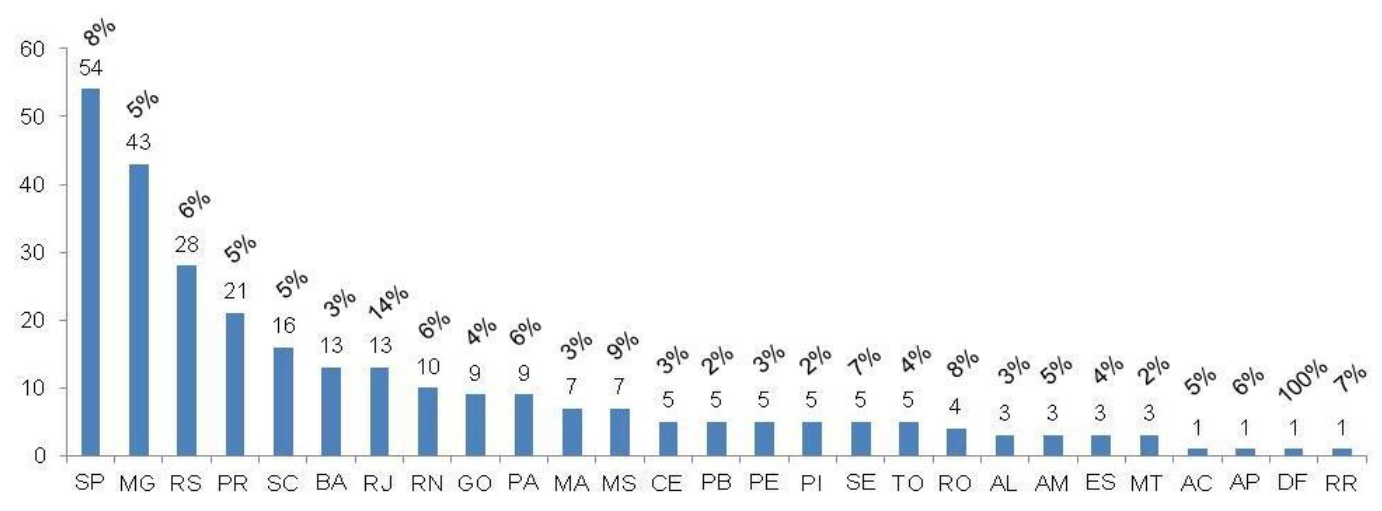

Fonte: Elaborado pelas autoras.

No Gráfico 1, é possível perceber que as UFs de SP, MG e RS são as que apresentam maior quantidade de municípios com informações coincidentes nas duas bases, evidenciando-se, mais uma vez, a participação das regiões Sudeste e Sul. No entanto, deve-se destacar que representativamente, o Distrito Federal se destaca com 100\%, por apresentar apenas um município e, os estados de RJ, MS, $\mathrm{RO}$ e SP foram os que apresentaram maior porcentagem de municípios com informações coincidentes, quando se relaciona com a quantidade de municípios existentes na UF.

\subsection{Coleta Seletiva}

Tem-se uma tendência mundial, nos últimos anos, de incentivo à coleta seletiva como forma de reaproveitamento dos produtos lançados no lixo para a fabricação de novos objetos através dos processos de reciclagem e reutilização, sob a justificativa de diminuição do desgaste do meio ambiente. Dessa forma, "o 


\section{Revista Nacional de}

Gerenciamento de Cidades

conceito de lixo vem sendo modificado, podendo ser entendido como, algo que pode ser útil e aproveitável pelo homem." (SILVA; LIVRAMENTO, 2014, p. 6).

Apesar da importância desse tipo de coleta, no Brasil são poucos os municípios (996) que realizam essa prática, de acordo com os dados da PNSB 2008 (MAPA 1).

\section{Mapa 1. Quantidade e representatividade da coleta seletiva nos municípios das Unidades da} Federação, de acordo com a base de dados da PNSB/IBGE 2008.

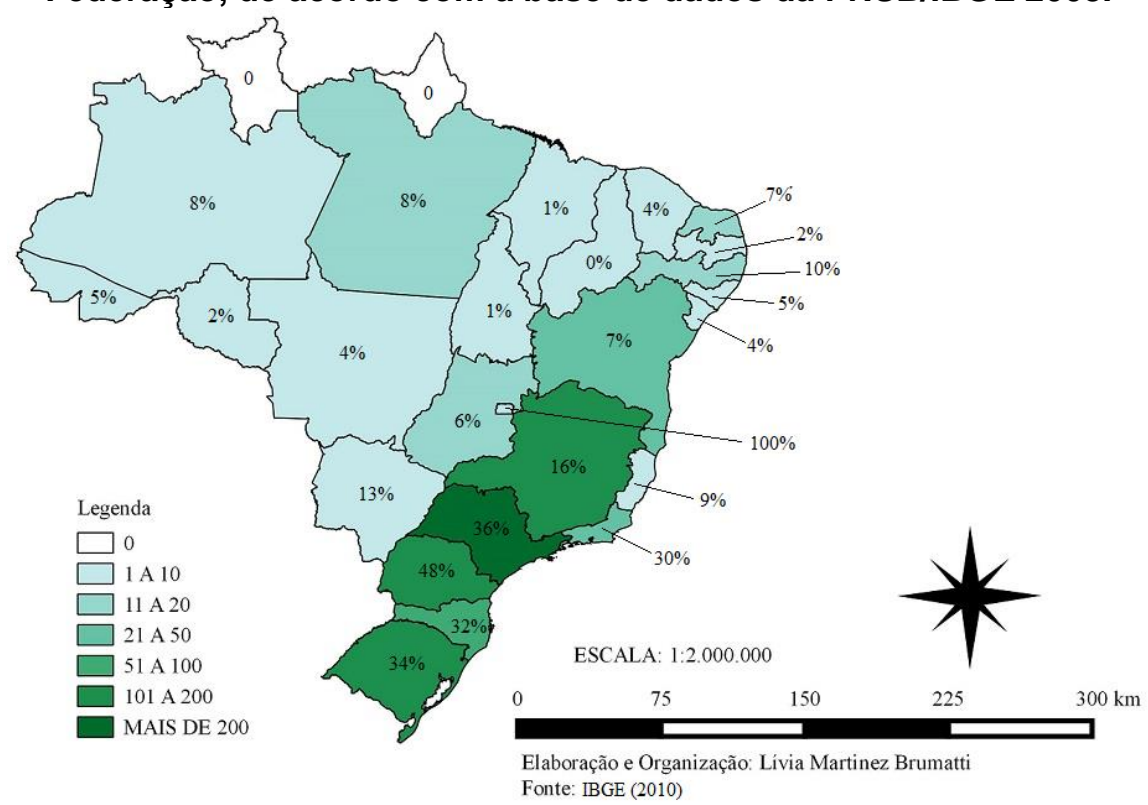

Pode-se perceber, do Mapa 1, que as regiões Sul e Sudeste são as que apresentam o maior número de municípios com a coleta seletiva, mas ainda assim, a abrangência da atividade não chega a 50\% dos municípios de todas as UFs.

Deve-se ressaltar, também, que esses dados foram coletados pela PNSB 2008 e, nesse mesmo ano, 39 municípios dos 372 respondentes ao SNIS, declararam existir a coleta seletiva, o que não coincide com o identificado pela PNSB. Essa divergência entre as bases pode ser proveniente de duas situações: ou os municípios declararam a informação errada quanto à efetividade da existência dessa atividade (indicando problemas na base do SNIS); ou, no caso da real existência da mesma, a metodologia de captação das informações, pela PNSB, 


\section{Revista Nacional de}

Gerenciamento de Cidades

pode ser ineficiente para demonstrar as realidades brasileiras, mesmo abrangendo todos os municípios do país, visto a morosidade na coleta e divulgação dos dados.

Ao mesmo tempo, a PNSB 2008 informou que em 18 outros municípios existia a coleta seletiva, sendo que os mesmos municípios declaram a não execução da atividade no SNIS, em 2008. O que pode ser um indicador da inexistência de um padrão nas categorias analisadas pelas duas bases, quando as mesmas tentam demonstrar a mesma informação ao público, ou uma divergência dos dados.

Há que se informar, também, que, dentre aqueles 39 municípios destacados anteriormente, para SNIS 2008, 5 municípios não declaram dados no ano de 2013, 12 outros negam a existência da coleta seletiva (agora coincidindo com os dados da PNSB 2008), e os demais 22 continuam afirmando a existência da atividade, mesmo que esta não tenha sido identificada pela PNSB.

Além disso, apesar de períodos distintos, dos 996 municípios que possuíam a coleta seletiva na PNSB, em 2008, 203 declaram não as possuir em 2013, na base do SNIS. Isso gera inquietação, pois não é possível confirmar se houve mesmo a interrupção da atividade, uma vez que não há um consenso da veracidade dos dados autodeclaratórios do SNIS como afirmam os autores Pupin e Borges (2015). Contudo, se for verídico o dado de que 203 municípios não fazem mais a coleta seletiva em 2013, tem-se condição preocupante, visto que a coleta seletiva é a principal forma de reciclagem, redução e reutilização dos resíduos provenientes do descarte.

De maneira geral, portanto, mesmo que o Poder Público opte pela utilização de uma base mais atualizada, como o SNIS, e/ou concentre suas atenções àqueles municípios cujos dados coincidam entre as duas bases e os anos analisados (2008 e 2013), ao partir do pressuposto de continuidade de declarações, apenas 138 municípios estariam aptos para uma resposta coerente às necessidades municipais, dado os informes (Gráfico 2). Lembrando ainda que a continuidade não reflete em veracidade de informes, mas como não se pode desconsiderar o esforço dos municípios em responder, pressupõe-se que sejam corretos. 


\section{Revista Nacional de}

Gerenciamento de Cidades

utilização está comprometida em decorrência dos seguintes fatores: a periodicidade da publicação dos dados da PNSB, pois a mesma não tem regularidade, ocorrendo de tempos em tempos, porém é uma pesquisa abrangente a todos os municípios do país; a metodologia de dados autodeclaratórios dos municípios pelo SNIS, pois estes podem não responder os dados, ou responder de forma incorreta; a elaboração e publicação dos dados, que em ambas as bases ocorrem dois anos após o recolhimento das informações, o que gera morosidade de intervenção pública, seja para as ações pontuais, seja para a prevenção de futuros problemas.

Outra dificuldade em relação às bases de dados se refere ao modo de divulgação das informações, pois as variáveis utilizadas nem sempre tem a mesma definição ou categorização, o que pode prejudicar a consulta.

Para a variável "coleta domiciliar regular de lixo" da PNSB, que tem sua correspondente na variável "coleta regular de resíduos sólidos domiciliares e públicos" no SNIS, apenas $5 \%$, do total de municípios do país, apresentaram informações compatíveis nas duas bases e anos analisados. Os demais 95\% municípios, ou não responderam ao SNIS (5.192 em 2008 e 1.998 em 2013), ou apresentaram informações divergentes nas comparações. Para a variável "coleta seletiva" tem-se que esta, ainda, é uma atividade pouco praticada nos diversos municípios do país, apesar da importância que a mesma tem ganhado contemporaneamente. Além disso, a quantidade de municípios com informações compatíveis nas duas bases é menor que na "coleta regular", correspondendo a $2,87 \%$ do total de municípios brasileiros.

Diante de todas essas dificuldades, é importante que o Poder Público utilize essas bases apenas como indicativos e não como dados efetivos da realidade. Além disso, a efetivação de Políticas Públicas adequadas depende da regularização e padronização das bases utilizadas, bem como de outras informações ou ações que podem não estar abrangidas nos questionários, como: a regularização da atividade informal; a colaboração da sociedade na separação; e a disposição do lixo produzido em locais adequados. 
Revista Nacional de

Gerenciamento de Cidades

\section{REFERÊNCIAS BIBLIOGRÁFICAS}

ALMEIDA, Ronise Nascimento et al. A problemática dos resíduos sólidos urbanos. Revista Interfaces Científicas - Saúde e Ambiente, Aracaju, v. 2, n. 1, 2013, p.25-36.

BRASIL. Lei $n^{\circ}$ 11.445, de 5 de janeiro de 2007. Diário Oficial [da] República Federativa do Brasil, Brasília, DF. 2007.2 Disponível em: <http://www.planalto.gov.br/ccivil_03/_ato2007-2010/2007/lei/111445.htm> Acesso: 20 mai. 2015.

Lei $n^{\circ}$ 12.305, de 2 de agosto de 2010. Diário Oficial [da] República Federativa do Brasil, Brasília, DF. 2010. Disponível em: <http://www.planalto.gov.br/ccivil_03/_ato2007-2010/2010/lei/112305.htm> Acesso: 21 mai. 2015.

IBGE. Instituto Brasileiro de Geografia e Estatística. Pesquisa Nacional de Saneamento Básico 2008 - Plansab 2008. 219 f. Rio de Janeiro: MP/IBGE. 2010. Disponível em: <http:// www.ibge.gov.br/home/estatistica/populacao/condicaodevida/pnsb2008/PNSB_2008.pdf>.

Acesso: 22 mai. 2015.

LEITE, Paulo R. Logística Reversa: meio ambiente e competitividade. $2^{\text {a }}$ Ed. São Paulo: Pearson Prentice Hall, 2009. 240 p.

MCIDADES. Ministério das Cidades. SNIS. Sistema Nacional de Informações sobre Saneamento. Diagnóstico do Manejo de Resíduos Sólidos Urbanos 2008. Brasília:

MCIDADES/SNSA, 2010. Disponível em: <http://www.snis.gov.br>. Acesso em 20 mai. 2015.

. SNIS. Sistema Nacional de Informações sobre Saneamento. Diagnóstico do Manejo de Resíduos Sólidos Urbanos 2013. Brasília: MCIDADES/SNSA, 2015. Disponível em: <http://www.snis.gov.br> Acesso em 20 mai. 2015.

PUPIN, Patricia. L. F; BORGES, Ana C. G. A vulnerabilidade dos dados dos Municípios Paulistas sobre Resíduos Sólidos no sistema autodeclaratório do SNIS. Revista VITAS - Visões Transdisciplinares sobre Ambiente e Sociedade, Ano V, n 9, 2015.

SÃO PAULO. (Estado) Secretaria do Meio Ambiente. Resíduos Sólidos. Secretaria do estado do Meio Ambiente, Coordenadoria de Planejamento Ambiental. São Paulo: SMA, 2010. 7 p. (Cadernos de Educação Ambiental, 6).

SILVA, Izabel C. A.; LIVRAMENTO, Darlan, E. A importância econômica, social e ambiental da coleta de resíduos sólidos realizada pelos coletores de materiais recicláveis do município de São Sebastião do Paraíso - MG. Revista de Iniciação Científica da LIBERTAS, São Sebastião do Paraíso, v. 4, n. 1, p.6-21, jul. 2014.

SINIR (2015). Sistema Nacional de Informações sobre a Gestão dos Resíduos Sólidos. Disponível em: <www.sinir.gov.br>. Acesso: mai. 2015. 